\title{
OVARIAN TORSION IN PREMENARCHAL GIRL
}

\author{
Jayasri Karem¹, Ravi Prasad Thota², Prathyusha Pudi ${ }^{3}$
}

\section{HOW TO CITE THIS ARTICLE:}

Jayasri Karem, Raviprasad Thota, Prathyusha Pudi. "Ovarian Torsion in Premenarchal Girl”. Journal of Evolution of Medical and Dental Sciences 2014; Vol. 3, Issue 72, December 22; Page: 15327-15330,

DOI: $10.14260 /$ jemds/2014/4064

\begin{abstract}
Prompt diagnosis is essential to ovarian salvage and high clinical suspicion is important in this regard. The diagnosis is confounded with more common abdominal complaints as constipation, diarrhea and UTI and with common surgical emergencies. Prompt diagnosis is difficult in low risk population such as young children. Herein we describe the case of 13 yrs old premenarchal girl presented with acute abdominal pain, diagnosed and treated for acute ovarian torsion.
\end{abstract}

KEYWORDS: Ovarian torsion, Premenarche, Fertility.

INTRODUCTION: Ovarian torsion is the fifth most common gynaecological surgical emergency accounting for $2-3 \%$ of cases of acute gynaecological complaints. It occurs at any age but most cases occur in the early reproductive age. Approximately $17 \%$ of cases have found to occur in premenarchal girl.

CASE REPORT: A 13 yrs old premenarchal girl came with complaint of pain in lower abdomen since 2 days and with history of one episode of vomiting. History of constipation present. On examination her ht: $152 \mathrm{~cm}$, wt: $67 \mathrm{kgs}$, BMI: $29 \mathrm{~kg} / \mathrm{m}^{2}$ Her pulse rate was $110 / \mathrm{min}$ and other vitals were normal. On her abdomen examination abdomen is distended, tense with tenderness more in right iliac fossa with dull note on percussion. On per rectal examination tender cystic swelling palpable separate from the uterus. Investigation were done total count was $13,500 /$ cumm and other parameters are with in normal limit. On USG uterus is $6.6 \times 2 \times 3.5 \mathrm{~cm}$ with ET8mm. A $7 \times 5 \mathrm{~cm}$ cyst noted with more cyst of $7.2 \times 5.5 \mathrm{~cm}$ adjacent to it was noted in right adnexal region, right ovary not visualized separately. Left ovary was $3.5 \times 3 \mathrm{~cm}$ cystic. Minimal free fluid noted. On Doppler study right adnexal region was cystic and hypo echoic without internal color uptake suggestive of torsion of ovary. On CT scan a cystic lesion measuring $7.8 \times 7.2 \times 7.3 \mathrm{~cm}$ in the right adnexa abutting a soft tissue mass with multiple cystic appearances measuring $8.2 \times 6.8 \times \times 7.1 \mathrm{~cm}$ noted in the midline causing indentation of bladder superiorly. No evidence of calcification Right ovary not visualized separately suggestive of torsion of ovary. Left ovary was $4.3 \times 3.8 \mathrm{~cm}$ cystic.

On laparotomy, $7 \times 7 \mathrm{~cm}$ hemorrhagic cystic lesion from right adnexa along with. A $6 \times 5 \mathrm{~cm}$ hemorrhagic cyst adjacent to the cyst and attached to it with a common pedicle. Torsion of the cyst noted. Free fluid present in the peritoneal cavity. Left ovary was enlarged and cystic. On histopathology, cut section of one lobe showed serous fluid and other lobe showed clotted blood. Microscopic appearance shows a cyst lined by inner granulose cell layer and outer theca interna cell layer. Numerous congested blood vessels with areas of haemorrhage. No evidence of malignancy. Suggestive of Follicular cyst.

DISCUSSION: Ovarian torsion is rare in premenarchal girl and it is a surgical emergency because of the potential for reproductive and hormonal compromise. It classically occurs unilaterally in a 
pathologically enlarged ovary. Right ovary undergoes torsion more often than the left ovary. Fewer than hail of ovarian torsion cases in pediatric patients involves cysts, teratomas or other masses. Ovarian tumors both benign and malignant are implicated in 50-60\% cases of torsion, involved masses are nearly all larger than 4-6cm. malignant tumors are much less likely to result in torsion than benign because of the presence of cancerous adhesion in the latter.

Clinical picture is nonspecific and children cannot always articulate their symptoms which often make the diagnosis a challenge. A gynecological examination with sonography should be included in diagnostic workup of young girl with abdominal complaints. Early recognition and prompt management yield significant reduction in morbidity and an increased likelihood of ovarian salvage.

\section{REFERENCES:}

1. Shust NM, Hendrickson DK, Ovarian Torsion: An unusual cause of abdominal pain in a young girl; American J Emergency Medicine, 1995 May; (3)307-9.

2. Quint EH, Smith YR: Ovarian Surgery in pre-menarchal girls; J Pediatric Adoloscent Gynecology 1999, Feb 12 (1)27-9.

3. Piippos, Mustaniemi L: Surgery of Ovarian Masses during Childhood and Adolescence: A report of 79 cases; J Pediatric Adolescent Gynecology 1999, Nov 12 (4); 223-7.

4. Neji K Milk K, Barounik: Management of Adnexal Torsion: Tunis Med 2003 Jun 81 (6); 415-8.

5. Emonts M, Doornewaard H, Admiraal JC; Adnexal Torsion in very young girls: Diagnostic pit falls; European J Obstetric gynecology Reproductive Biology 2004 Oct 15; 116(2); 207-10.

6. Karnik AS, Sainani Md N, Kamat Md N: Sequential Bilateral Ovarian Torsion in Normal Ovaries in a Pre-pubertal child; J Clinical Ultrasound 2006, Jan 34(1): 33-7.

7. Oalsner G Shashar D: Ednexal Torsion: J Clinical Obstetric and Gynecology 2006 Sep 49(3): 45963.

8. Chang YJ, Yan DC, Cong MS: Adnexal Torsion in Children: J Pediatric Emergency Care 2008 Aug 24(8): 534-7.

9. Rollene N, Nunn M, Wilson T: Recurrent Ovarian Torsion in a Pre menarchal Adolescent Girl: Contemporary Surgical Management: J Obstetric Gynecology 2009 Aug 114(2 PT 2): 422-4.

10. Brian T Kloss, Lowise A Prince: Ovarian Torsion in a Pre-pubertal Girl: International J of Emergency Medicine Jun 2009(2): 127-128.

11. Mary L, Hilfiker, David Preskill, Ovarian Torsion in a Pre-pubertal Girl: Pediatric EndoSurgery and Innovative Techniques: Vol 4; Issue 1; Sep 14, 2010; 53-55.

12. Jennifer Eng Lunt, Heather Appel Baun, Jahn Avarella; Pediatric and Adolescent Ovarian Torsion; American College of Physicians News, Dec 2011.

13. Mathew F Ryon and Bobby K Desai: Ovarian Torsion in a 5year old- A case Report and Review; Case Reports in Emergency Medicine Vol 2012.

14. Shauna Duigenan, Esther Oliva, Susanna I Lee: Ovarian Torsion: Diagnostic Features on CT and MRI with pathological Correlation: American Journal of Roentgenology. Feb 2012, Vol. 198 No 2, W122-W131.

15. Hong Quian Liv, Xiangao Wang, Ovarian Masses in Children and Adolescents in China; Analysis of 203 cases: J of Ovarian Research 2013 July 6; 47. 


\section{CASE REPORT}

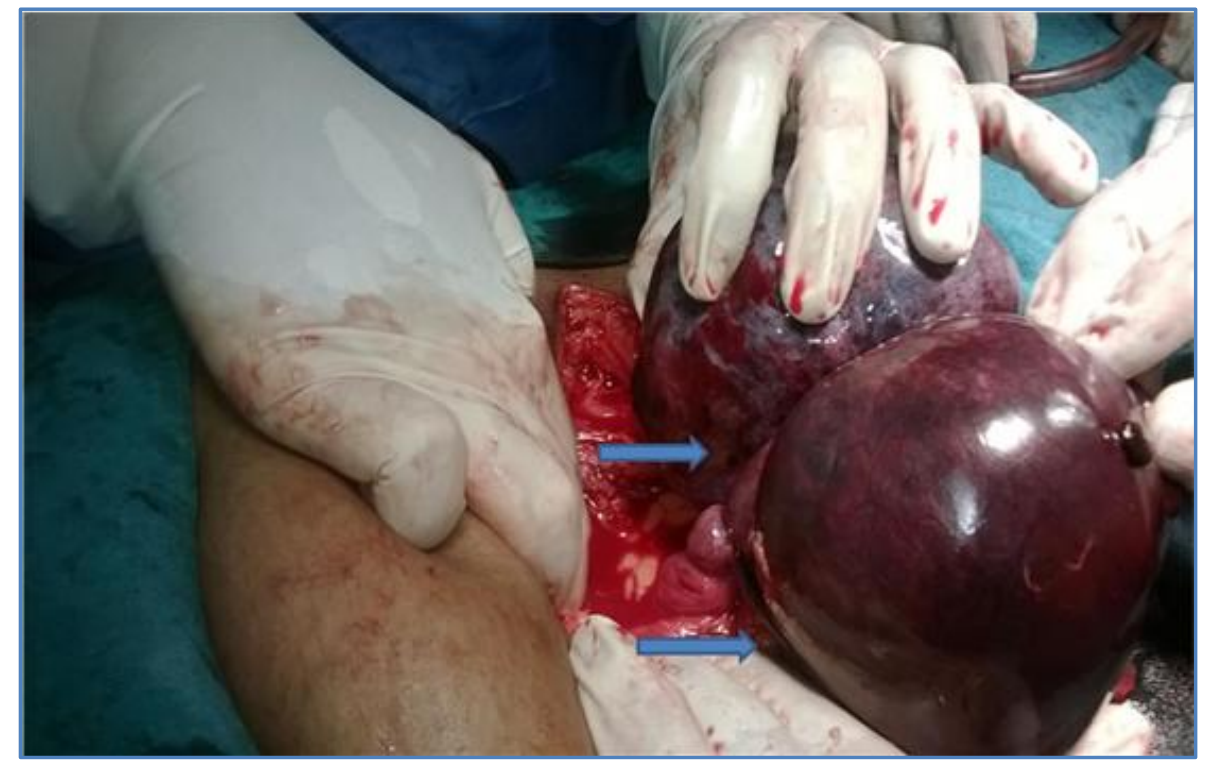

Right Ovarian cyst with 2 lobules attached to a common pedicle

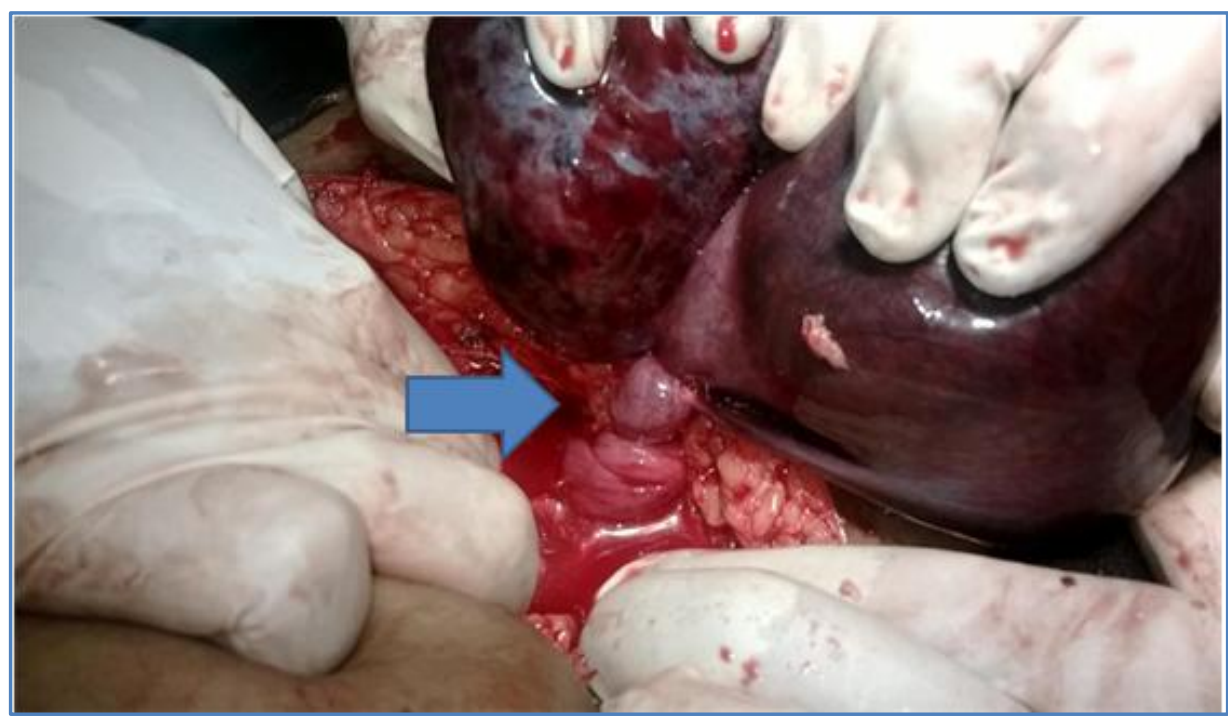

A Twisted ovarian cyst with gangrenous changes above the torsion point 


\section{AUTHORS:}

1. Jayasri Karem

2. Ravi Prasad Thota

3. Prathyusha Pudi

\section{PARTICULARS OF CONTRIBUTORS:}

1. Assistant Professor, Department of Obstetrics and Gynaecology, Katuri Medical College and Hospital, Chinakondrupadu, Guntur.

2. Professor and HOD, Department of Obstetrics and Gynaecology, Katuri Medical College and Hospital, Chinakondrupadu, Guntur.

3. $2^{\text {nd }}$ Year Post Graduate Student, Department of Obstetrics and Gynaecology, Katuri Medical College and Hospital, Chinakondrupadu, Guntur.

\section{NAME ADDRESS EMAIL ID OF THE CORRESPONDING AUTHOR:}

Dr. Jayasri Karem,

Assistant Professor, Department of Obstetrics and Gynaecology, Katuri Medical College and Hospital, Chinakondrupadu, Guntur, Andhra Pradesh. E-mail: jayaran83@gmail.com

Date of Submission: 29/11/2014. Date of Peer Review: 01/12/2014. Date of Acceptance: 16/12/2014. Date of Publishing: 22/12/2014. 